Technological University Dublin ARROW@TU Dublin

\title{
A contemporary multi-modal mechanical approach to training monitoring in elite professional soccer
}

\author{
Adam Owen \\ Universite Claude Bernard (Lyon I), adamowen@outlook.com \\ Leo Djaoui \\ Universite Claude Bernard (Lyon I) \\ Matthew Newton \\ University of the West of Scotland
}

See next page for additional authors

Follow this and additional works at: https://arrow.tudublin.ie/ittsciart

Part of the Sports Sciences Commons

\section{Recommended Citation}

Owen, Adam \& Djaoui, Léo \& Newton, Matt \& Malone, Shane \& Mendes, Bruno. (2017). A contemporary multi-modal mechanical approach to training monitoring in elite professional soccer. Science and Medicine in Football. 1-6. 10.1080/24733938.2017.1334958.

This Article is brought to you for free and open access by the School of Science and Computing at ARROW@TU Dublin. It has been accepted for inclusion in Articles by an authorized administrator of ARROW@TU Dublin. For more information, please contact arrow.admin@tudublin.ie, aisling.coyne@tudublin.ie, gerard.connolly@tudublin.ie.

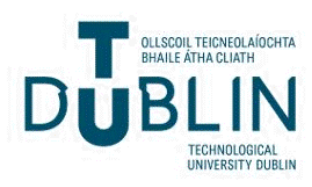




\section{Authors}

Adam Owen, Leo Djaoui, Matthew Newton, Shane Malone, and Bruno Mendes

This article is available at ARROW@TU Dublin: https://arrow.tudublin.ie/ittsciart/125 
See discussions, stats, and author profiles for this publication at: https://www.researchgate.net/publication/318379665

\section{A contemporary multi-modal mechanical approach to training monitoring in elite professional soccer}

Article in Science and Medicine in Football · July 2017

DOI: 10.1080/24733938.2017.1334958

CITATIONS

47

5 authors, including:

Adam L Owen

Claude Bernard University Lyon 1

87 PUBLICATIONS 2,688 CITATIONS

SEE PROFILE

Matt Newton

University of the West of Scotland

9 PUBLICATIONS 267 CITATIONS

SEE PROFILE
7,996

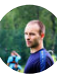

Léo Djaoui

Claude Bernard University Lyon 1

16 PUBLICATIONS 458 CITATIONS

SEE PROFILE

Shane Malone

Technological University Dublin - Tallaght Campus

67 PUBLICATIONS 1,561 CITATIONS

SEE PROFILE

Some of the authors of this publication are also working on these related projects:

Observação e Análise do Jogo de Futebol View project

Ergonomics of Hurling: An integrated performance analysis, physiological and metabolic evaluation approach View project 


\section{A contemporary multi-modal mechanical approach to training monitoring in elite professional soccer}

\section{Adam L. Owen, Leo Djaoui, Matthew Newton, Shane Malone \& Bruno Mendes}

To cite this article: Adam L. Owen, Leo Djaoui, Matthew Newton, Shane Malone \& Bruno Mendes (2017): A contemporary multi-modal mechanical approach to training monitoring in elite professional soccer, Science and Medicine in Football, DOI: 10.1080/24733938.2017.1334958

To link to this article: http://dx.doi.org/10.1080/24733938.2017.1334958

曲 Published online: 12 Jul 2017.

Submit your article to this journal $[\pi$

Q View related articles $₫$

View Crossmark data 


\title{
A contemporary multi-modal mechanical approach to training monitoring in elite professional soccer
}

\author{
Adam L. Owen ${ }^{\mathrm{a}, \mathrm{b}}$, Leo Djaoui ${ }^{\mathrm{b}}$, Matthew Newtonc, Shane Malone ${ }^{\mathrm{d}}$ and Bruno Mendes ${ }^{\mathrm{a}}$ \\ aSport Lisboa e Benfica Sport Science Department, BenficaLAB, Lisbon, Portugal; 'bentre de Recherche et d'Innovation sur le Sport, Université \\ Claude Bernard Lyon.1, Lyon, France; cUWS Centre for Football Research, University of the West of Scotland, Glasgow, Scotland; dHuman \\ Performance Lab, Institute of Technology Tallaght, Tallaght, Ireland
}

\begin{abstract}
Objectives: Understanding movements and mechanical demands of elite soccer players during training and competitive stressors is important for the support provision of player performance. Continued appreciation to quantify and monitor training load (TL) is apparent, however reporting multi-modal approaches in-line with competitive match-play demands remain limited. The investigation aimed to highlight a multimodal training monitoring method and its relationship to match-play.

Subjects: 29 elite European soccer players participated were assessed $(26.7 \pm 4.07$ years, height $183.4 \pm$ $5.87 \mathrm{~cm}$, body mass $78.4 \pm 8.03 \mathrm{~kg}, V_{\mathrm{O}_{2} \max } 57.55 \pm 5.32 \mathrm{ml} \mathrm{kg}^{-1} \cdot \mathrm{min}^{-1}$ and body composition $54.12 \pm 13.65$ $\mathrm{mm}$ ) with daily TL and competitive match-load data in order to quantify the relationship between both.

Methods: Key match-day (MD) data and TL was analysed across a 20-week in-season period.

Results: Results reported significant TL differences between training days (TDs) and TDs and competitive MD data, in addition to significant differences between TDs for both volume- and intensitysession scores $(p<0.05)$. No differences were found between MD-1 and MD-2 session scores.

Conclusion: To specific specific multi-modal approach used allows practitioners to combine key mechanical volume and intensity metrics as part of an athlete or player monitoring strategy and ensure a greater focus on targeted physical stressors.
\end{abstract}

ARTICLE HISTORY

Accepted 15 May 2017

\section{KEYWORDS}

Soccer; GPS analysis; tapering; periodisation; training load

\section{Introduction}

Training load (TL) monitoring and assessment of elite players in professional soccer through the use of global positioning systems (GPS) is well documented and performed on a daily basis. Recently, monitoring TL has primarily been proposed in order to ensure that optimal workloads are induced to maximise physical performance and reduce the occurrence of injury or illness (Owen et al. 2016; Gabbett et al. 2016). According to the literature, TL metrics are generally reported in isolation and without association to training outcomes. As a result, understanding the physical profile of players training and competitive demands via testing and assessment is of paramount importance for support provision and player development in line with player's career. Ensuring player's capability to tolerate the demands of their sport and reproduce high performance levels without incurring injuries, and thus remain available for selection, is of paramount importance (Orchard 2009; Gabbett 2016). Importantly, Eirale et al. (2013) reported how greater training and match-play availability of an entire playing squad significantly led to a team's greater chance of success.

Literature examining TL and links with match injury rates have recently focussed attention around the on-pitch training intensity and volume aspects (Malone et al. 2015; Owen et al. 2015). However, it is the understanding of the optimal TL at which adaptation occurs based on match-play activity, without raising the risk of injury that should be a key priority of developing a monitoring and assessment strategy. Developing a clear association of combined TL metrics and training outcome in line with the sports competitive demands should be of great value. It is well reported that team sport success is dependent upon a number of variants (e.g., player skill, fitness, squad size, tactics and psychological factors), and as a result, contemporary research continues to show an ever-growing appreciation for the use of tools to quantify and monitor TL of professional soccer players (Buchheit 2014; Owen et al. 2014). Accordingly, at the elite level of sport, the use of GPS is becoming more commonplace with the main aim to report daily demands imposed on both the individual and collective team, although it is widely accepted that the use of GPS in elite soccer can provide coaches with a detailed summary of the TL (intensity $\times$ duration) (Scott et al. 2013). GPS literature has generally provided readers with isolated metric outcomes (total distance covered [TDC], high-speed running [HSR], sprint, acceleration and deceleration) (Hill-Haas et al. 2011; Owen et al. 2014; Malone et al. 2015). According to recent research, the continued requirement and demand to perform explosive eccentric actions such as change of directions, accelerations and decelerations seem particularly damaging to the muscle (Raastad et al. 2010; Young et al. 2012; Silva et al. 2014). As a result, the combination of the key reported metrics may be seen as an interesting concept to challenge the current reports.

It has been noted that periodised approaches to elite level soccer training may facilitate longitudinal progressive training adaptations and concurrently reduce injury risk (Mallo \& Dellal 
2013; van der Horst et al. 2015; Owen et al. 2016, 2017). Malone et al. (2015) quantified the seasonal training-load among an elite English Premier League squad and observed that a microcycle periodisation of TL was typically confined to the day preceding a competitive match day (MD-1), whereas no differences were apparent during MD-2-MD-5. Furthermore, findings from Owen et al. (2017) indicated that it is possible to maintain a uniformed and structured mesocycle whilst inducing variation of the TL output during microcycle periods among elite professional players. Further findings from this study also revealed how a tapering approach may be adopted to add significant variation in positional demands throughout a microcycle. As previously discussed, literature in this area still reports player TLs as individual metrics with no reference to a combined approach highlighting both volume and intensity represented values. Even though this is a novel and well reported subject to date, to our knowledge, there are no specific investigations studying a multimodal approach to the monitoring of training volume and intensity.

Recent research indicates that despite the availability of more detailed TL indicators nowadays, the evidence about the usefulness in relation to training outcomes is rare and as a result suggests that future research should focus attention on combining individual characteristics for reporting (Jaspers et al. 2017). Being able to provide clarification of the TL across a microcycle may lead to a more comprehensive understanding of tapering approaches in elite professional soccer. To date, no published literature reports a multimodal approach to monitoring training in direct relationship with competitive soccer match-play at the elite level. The primary aim of this particular research investigation is to highlight a novel, contemporary and clear multi-metric monitoring method highlighting the training demands in direct relation to matchplay and reveal its representation of a tapering structure for TL markers across in-season microcycles.

\section{Methods}

\section{Participants}

Twenty-nine senior male European professional soccer players participated within the investigation. At the time of the study, the players were competing in the Swiss Professional soccer league. Thirteen of the players involved were members of their national team. Players' age, height, body mass, maximal aerobic capacity and sum of eight skinfold sites were $26.7 \pm 4.0$ years, $183.4 \pm 5.8 \mathrm{~cm}, 78.4 \pm 8.0 \mathrm{~kg}, 57.5 \pm 5.3 \mathrm{ml} \cdot \mathrm{kg}^{-1} \cdot \mathrm{min}^{-1}$ and $54.1 \pm 13.6 \mathrm{~mm}$, respectively. Informed consent was received from all players to include their data after a brief but detailed explanation about the investigation. Players were told that they were free to withdraw their information and data from the study at any time and the study conducted was fully approved by the involved Sports Science and Medical Department at the Football Club precommencement of the monitoring. Furthermore, the study met the ethical standards of the researching university and was conducted in accordance with the principles outlined in the Declaration of Helsinki.

\section{Procedures, content and study design}

The study was conducted over a 20-week period during the midphase of the competitive season. This mid-season phase was used for the assessment as to ensure minimal fitness changes and subsequent metric changes per training sessions. Only daily analysis from training weeks situated within a 1-game week has been used within the study in order to track the training demands across the 20 microcycle phases. Players included within the data collection were only inclusive of players who had performed greater than 80 min of the competitive match-play at the end of the analysed week. For the reliability and validity of the study, only data from players who performed the full session duration have been used, withdrawing the data from players whose TL was manipulated during this time due to fatigue management or injury. Players were instructed to maintain normal daily food and water intake. No additional dietary interventions were undertaken throughout the investigation.

\section{Training assessment}

Throughout the investigation, a total number of 80 training session data were collected for assessment and analysis. The data assessed included 20 microcycles consisting of 1-week blocks of full training sessions per player: $20 \times M D-4,20 \times M D-3,20 \times M D-2$, $20 \times$ MD-1. No other data pre-MD-4 were considered for analysis as they did not have any specific on pitch content of adequate TL. All training sessions within the investigation period were played on an outdoor grass training field with an average temperature of $10.2 \pm 3.11^{\circ} \mathrm{C}$. Goalkeeper's data were excluded from the study and the data analysis. All players were fully familiarised with the use of GPS units worn throughout the investigation. During the investigation, all training sessions were preceded by a standardised warm-up period of 15 min prior to the initiation of the training session. The microcycles selected for assessment were as a result of them including full-training weeks following a 1-game period and minimise the potential for accumulative fatigue build-up and variations in the metrics assessed. In addition, these weeks were chosen on the basis that 1-game and 4-training sessions were performed within the week following 1 day off.

\section{Time motion analysis (GPS data)}

Each individual player's movement demands for each training session and matches were tracked using a $10-\mathrm{Hz}$ GPS device (Viper, Statsport, Ireland) as used in previous studies (Varley et al. 2012; Gaudino et al. 2015). Research has shown this system to be a valid and reliable assessment for monitoring team player's movement demands (Jennings et al. 2010; Randers et al. 2010). For the purpose of this study, the 4 key variables recorded throughout the sessions included TDC, HSR (19.8-25.2 $\left.\mathrm{km} \cdot \mathrm{h}^{-1}\right)$, sprint distance (SpD: $>25.2 \mathrm{~km} \cdot \mathrm{h}^{-1}$ ) and the sum of high intensity efforts which is the total number of high accelerations and decelerations (SumA:D $>4 \mathrm{~m} \cdot \mathrm{s}^{-2}$ ). All variables recorded for assessment were reported in both absolute $(\mathrm{m})$ and relative terms $(\mathrm{m} \cdot \mathrm{min})$. For the purpose of this 
Table 1. Categorisation of volume and intensity metrics.

\begin{tabular}{|c|c|c|c|}
\hline $\begin{array}{l}\text { Volume } \\
\text { metric } \\
\text { number }\end{array}$ & Volume metrics & $\begin{array}{c}\text { Metric } \\
\text { number }\end{array}$ & $\begin{array}{l}\text { Intensity metrics = volume } \\
\text { metrics/session duration }\end{array}$ \\
\hline 1 & $\begin{array}{l}\text { TDC average maximum } \\
\text { match score }(\%)\end{array}$ & 1 & $\begin{array}{l}\text { TDC.min/average } \\
\text { maximum match score }\end{array}$ \\
\hline 2 & $\begin{array}{l}\text { HSR/average } \\
\text { maximum match } \\
\text { score }\end{array}$ & 2 & $\begin{array}{l}\text { HSR.min/average } \\
\text { maximum match score }\end{array}$ \\
\hline 3 & $\begin{array}{l}\text { SpD/average } \\
\text { maximum match } \\
\text { score }\end{array}$ & 3 & $\begin{array}{l}\text { SpD.min/average } \\
\text { maximum match score }\end{array}$ \\
\hline 4 & $\begin{array}{l}\text { SumA:D/average } \\
\text { maximum match } \\
\text { score }\end{array}$ & 4 & $\begin{array}{l}\text { SumA:D.min/average } \\
\text { maximum match score }\end{array}$ \\
\hline
\end{tabular}

Volume and intensity score data represented as \% of players maximum match data.

TDC: total distance covered; HSR: high-speed running; SpD: sprint distance.

study, the specific speed thresholds set were in line with previous research (Dellal et al. 2011) and the average values per player taken from the complete training sessions were used for analysis in relation with their maximum competitive match-play data. Maximum MD data were used as the benchmark for the microcycle analysis in order to represent the data as a percentage of the player maximal capacity and physical potential.

\section{Load management analysis (GPS data)}

Developing a multimodal daily and weekly score for both volume and intensity markers in order to represent as both individual and collective load values, a contemporary mechanical load management analysis technique was devised incorporating four volume (TDC; HSR; SpD; SumA:D) and four intensity (TDC.min; HSR.min; SpD.min; SumA:D.min) GPS metrics. In order to attain the daily volume and intensity scores, average individual player data were pooled (i.e., as shown in the below calculation) to provide a squad average to create an initial session metric outcome score (Table 1). The mean individual data assessed were then compared to the average maximum individual competitive match-play metric achieved and reported as a percentage figure. The percentage volume and intensity of the session were generated through the following calculation:

\section{Statistical analysis}

Before using parametric tests, the assumption of normality was verified using the Shapiro and Wilkinson test. The use of one-way analysis of variance for repeated measures to exam- ine the difference in the GPS metrics collected between days. When significant $P$ values were observed within the data $(P<0.05), t$-test paired comparisons were used in conjunction with Holm's Bonferroni method for controlling type 1 error (Holm 1979) to determine significant differences with a $P<0.005$ for the 10 between-days comparisons assessed, and with a $P<0.0017$ for the 28 between-metrics comparisons assessed.

The effect sizes (ES) were calculated for all paired comparisons and evaluated with the method described by Cohen (1988) (small: <0.50, moderate: $0.50-0.80$ and large: $>0.80$ ).

\section{Results}

The results are expressed as mean \pm standard deviation and all variables were reported followed a normal distribution $(P<0.05)$. Differences were found between training days (TDs), and between TDs and competitive MD data in all metrics used and assessed in addition to differences highlighted between days for both volume and intensity session scores $(P<0.05)$. Session scores for $M D$ were significantly higher than MD-1 (ES: range 0.98-1.34), MD-2 (0.99-1.34), MD-3 (0.41-0.50) and MD-4 (0.71-1.07); MD-3 significantly higher than MD-1 (0.71-1.09), MD-2 (0.74-1.10) and MD-4 (0.40-0.75); MD-4 significantly higher than MD-1 (0.28-0.36) and MD-2 (0.33-0.42); however, no differences were found between MD-1 and MD-2 (Figure 1).

Furthermore, each individual day was significantly different in \%SumA:D (0.46-1.51) and \%TDC.min (0.33-1.71). In \%TDC, \%HSR and \%HSR.min, MD was significantly higher than MD-3 (0.50-0.78), MD-4 (1.13-1.34), MD-2 (1.37-1.58) and MD-1 (1.44-1.60); MD-3 was significantly higher than MD-4 (0.77-1.07), MD-2 (1.03-1.55) and MD-1 (1.08-1.68); and MD-4 was significantly higher than MD-2 (0.51-0.83) and MD-1 (0.56-1.00). In \%SpD and \%SpD.min, MD was significantly higher than MD-3 (0.32), MD-4 (1.18-1.34), MD-2 (1.26-1.44) and MD-1 (1.24-1.44); MD-3 was significantly higher than MD-4 (0.86-1.01), MD-2 (0.93-1.11) and MD-1 (0.93-1.12); and MD-4 was significantly higher than MD-2 (0.28). In \%SumA:D.min, MD was significantly higher than MD-4 (0.29), MD-2 (0.82) and MD-1 (0.64); MD-3 and MD-4 were significantly higher than MD-2 (0.65-0.98) and MD-1 (0.37-0.75); MD-1 was significantly higher than MD-2 (0.48) (Figure 2).

In the day-to-day analysis, significant differences were found between metrics. All differences are presented in Table 2.

$$
\text { Session Volume Score }=\frac{(\text { Volume Metric 1, 2, 3, } 4 \text { represented as a \% of Max Match Data) }}{4}
$$

Session Intensity Score $=\frac{(\text { Intensity Metric 1, 2, 3, 4 per session duration [min] represented as a \% of Max Match Data) }}{4}$ 


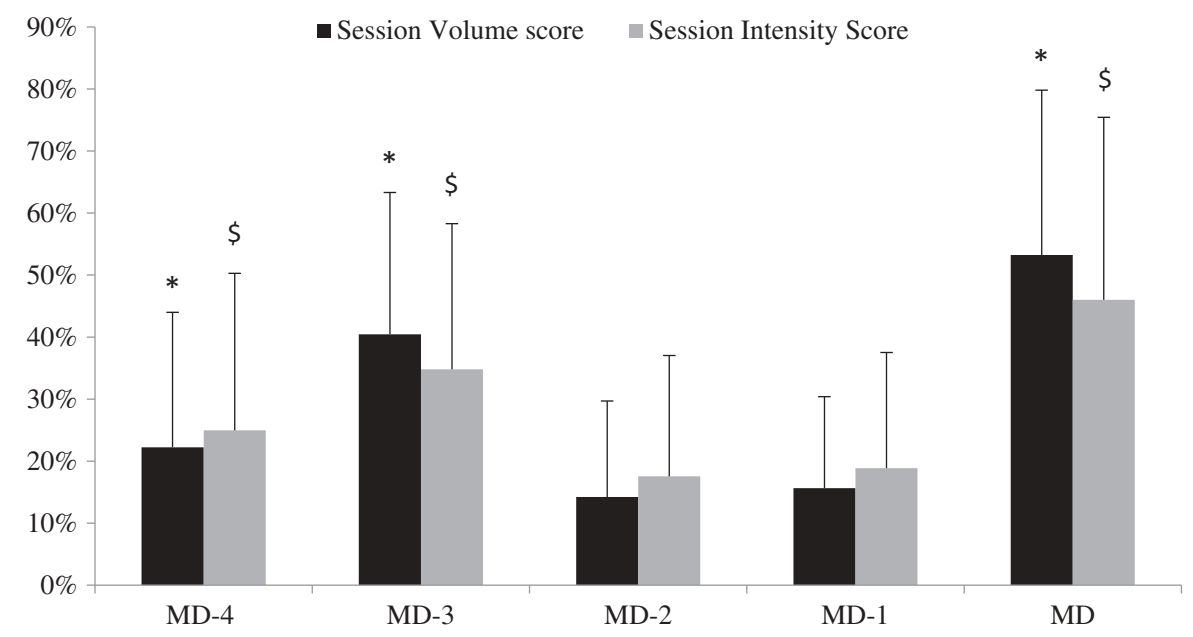

Figure 1. Graph to show the total volume and total intensity markers per day across the training microcycle represented as a \% of maximum match day data. *Levels of significance found for session volume score between each training day across the microcycle $(P<0.005) .{ }^{*}$ No level of significance found for session volume score between MD-2 and MD-1. ${ }^{5}$ Levels of significance found for session intensity score between each training day across the microcycle $(P<0.005)$.

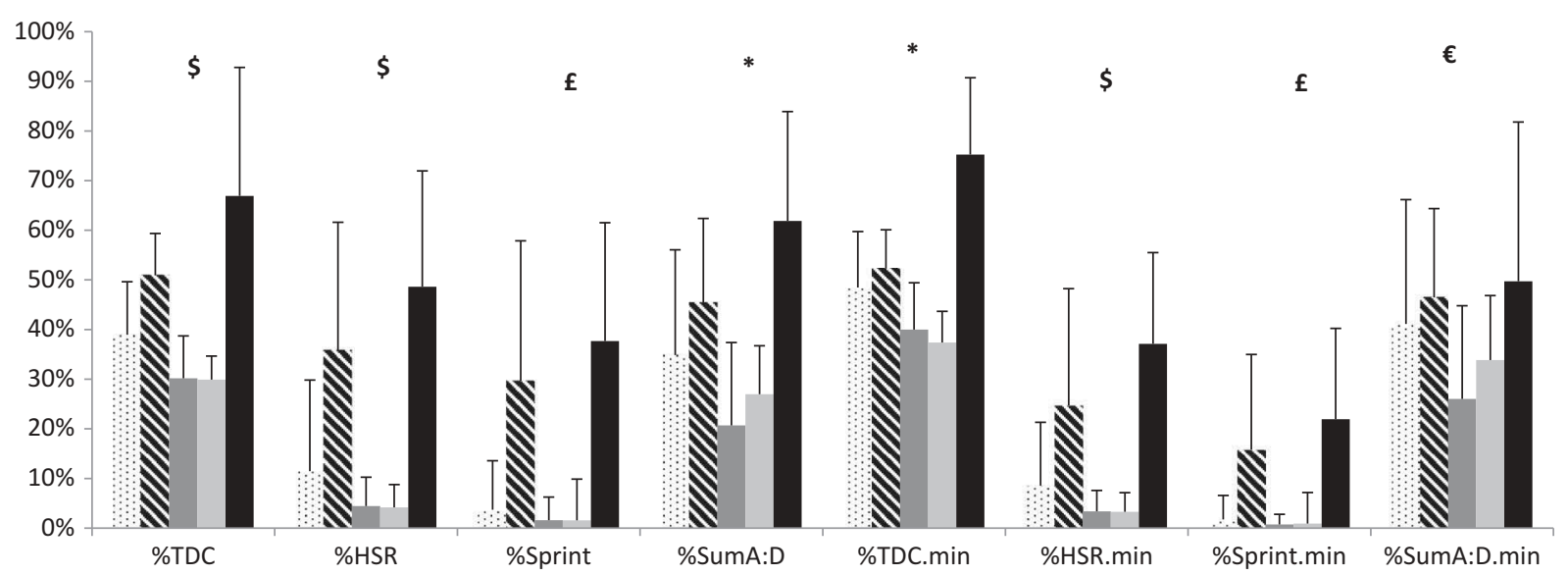

Figure 2. Average squad \% of maximum competitive match GPS values across both volume and intensity metrics.

${ }^{*}$ All values significantly different $(P<0.005)$. ${ }^{\$}$ All values significantly different except MD-1 vs. MD- $2(P<0.005) .{ }^{⿷}$ All values significantly different except MD-1 vs. MD-2 and MD-4 $(P<0.005)$. ${ }^{\epsilon}$ All values significantly different except MD-3 vs. MD and MD-4 $(P<0.005)$.

Table 2. Percentage of maximal volume and intensity match GPS metrics across competitive mesocycles in professional soccer players.

\begin{tabular}{|c|c|c|c|c|c|c|c|c|c|}
\hline Days & & $\begin{array}{c}\% \\
\text { TDC }\end{array}$ & $\begin{array}{c}\% \\
\text { HSR }\end{array}$ & $\begin{array}{c}\% \\
\text { SpD }\end{array}$ & \%SumA:D & $\begin{array}{c}\% \\
\text { TDC. } \\
\text { min }\end{array}$ & $\begin{array}{c}\% \\
\text { HSR. } \\
\text { min }\end{array}$ & $\begin{array}{c}\% \\
\text { SpD. } \\
\text { min }\end{array}$ & $\begin{array}{c}\% \\
\text { SumA: } \\
\text { D.min }\end{array}$ \\
\hline \multirow[t]{2}{*}{ MD-4 } & $m$ & $39^{\mathrm{dh}}$ & $11^{f}$ & $4^{g}$ & $35^{\text {ah }}$ & $48^{*}$ & $9^{b}$ & $2^{c}$ & $41^{\mathrm{a}, \mathrm{d}}$ \\
\hline & sd & 11 & 18 & 10 & 21 & 11 & 13 & 5 & 25 \\
\hline \multirow[t]{2}{*}{ MD-3 } & $m$ & $51^{e}$ & $36^{\mathrm{cf}}$ & $30^{\mathrm{bf}}$ & $45^{h}$ & $52^{\mathrm{a}}$ & $25^{c}$ & $16^{*}$ & $46^{d}$ \\
\hline & sd & 8 & 26 & 28 & 17 & 8 & 24 & 19 & 18 \\
\hline \multirow[t]{2}{*}{ MD-2 } & $m$ & $30 *$ & $4^{f}$ & $2^{g}$ & $21^{*}$ & $40^{*}$ & $3^{b}$ & $1^{c}$ & $26^{*}$ \\
\hline & sd & 9 & 6 & 5 & 17 & 9 & 4 & 2 & 19 \\
\hline \multirow[t]{2}{*}{ MD-1 } & $m$ & $30 *$ & $4^{f}$ & $2^{g}$ & $27^{*}$ & $37^{*}$ & $3^{b}$ & $1^{c}$ & $34^{*}$ \\
\hline & sd & 5 & 5 & 8 & 10 & 6 & 4 & 6 & 13 \\
\hline \multirow[t]{2}{*}{ MD } & $m$ & $67^{*}$ & $49^{h}$ & $38^{f}$ & $62^{b}$ & $75^{*}$ & $37^{c}$ & $22^{*}$ & $50^{b}$ \\
\hline & sd & 26 & 23 & 24 & 22 & 15 & 18 & 18 & 32 \\
\hline Weekly & $m$ & $43^{*}$ & $21^{*}$ & $15^{f}$ & $37^{\mathrm{h}}$ & $50^{*}$ & $16^{\mathrm{c}}$ & $8^{*}$ & $40^{d}$ \\
\hline average & sd & 20 & 25 & 24 & 22 & 17 & 20 & 15 & 24 \\
\hline
\end{tabular}

*Significantly different from all others $(P<0.0017) ; \mathrm{a}, \mathrm{b}, \mathrm{c}, \mathrm{d}, \mathrm{e}, \mathrm{f}, \mathrm{g}, \mathrm{h}$ significantly different from all except from \%TDC, \%HSR and \%SumA:D.min, respectively $(P<0.0017)$.

\section{Discussion}

The primary aim of this investigation was to examine a contemporary multi-metric method and reveal its representation of a tapering structure for both mechanical volume and intensity markers across an in-season microcycle. The study was performed with professional soccer players playing within a European league as to ensure the data added significance to sparse published literature in this area of research. Results from the study have shown that this specific multi-modal approach does reveal a tapering approach across the 20-weekly microcycles analysed and highlights this method as a potential way of monitoring training patterns of professional soccer players. The periodised approach used within this study has revealed significant TL variations in both key session volume and session intensity scores when assessed across the microcycle $(P<0.05)$. Findings from the study concur with traditional periodisation or tapering models only using one metric methods in reporting 
the training outcomes, reporting how TL should vary in order to facilitate optimal physiological adaptation (Malone et al. 2015; Owen et al. 2017). Recent literature has reported that enabling variation among specific training parameters may maximise training adaptations (Impellizzeri et al. 2004; Kelly \& Coutts 2007) whilst minimising the accumulative effects of fatigue and subsequently decreasing monotony and training strain (Issurin 2010).

Malone et al. (2015) quantified the seasonal TL in elite English Premier League players and found that the tapering strategy used typically confined significant TL variation to MD1. Additionally, Malone et al. (2015) suggested this as a method used to unload players the day preceding matches in an attempt to increase player readiness. Findings from the current investigation however have revealed significant differences between the session volume score between each specific TD revealing a planned periodised approach to both the volume and intensity metrics assessed.

Further analysis based on the volume TL metrics highlighted a reduced TL (i.e., both volume and intensity markers) in MD-1 and MD-2 compared to MD, MD-3 and MD-4, except for $\% \mathrm{SpD}$ and \%SpD.min that were also reduced in MD-4. It could be suggested that these particular GPS metrics were significantly affected based on the fact that they represent the most intense physical activity. As a result of these findings, use of such metrics in a multimodal periodisation monitoring approach supports the key elements of monitoring elite soccer players: maximising training performance (Hill-Haas et al. 2011; Owen et al. 2012), ensure players are protected from rapid overloaded training spikes and subsequent injuries (Opar et al. 2012; Gabbett 2016) and ensure training durability values are met (Malone et al. 2016).

Although the tapering strategy used in this study from a volume score perspective revealed no significant difference between MD-2 and MD-1, previous findings by Owen et al. (2016) proposed that a reduced TL should be implemented latterly within the training week to ensure that fatigue accumulation is managed accordingly and tapered to facilitate optimal preparation for subsequent match performance. More recently, tapering strategies among elite level soccer players have shown both a reduced training volume and intensity when approaching competitive MD situations in conjunction with significant daily variance (Owen et al. 2017). In line with Owen et al. (2017) and Malone et al. (2015), this current investigation has shown MD-4 and MD-3 to be the highest intensity and volume days within the training microcycle and highlights a significant difference between other days in terms of TL except when compared with MD data. The significant increase in the TL values on MD-3 is suggested to be as a result of the $>$ TDC $(51 \% \pm 8)$ and subsequent TDC . $\min ^{-1}(52 \% \pm 8)$ when compared to MD data. Impellizzeri et al. (2004) also described how TL was at its highest on MD-4 and MD-3 when compared to any other TD across a microcycle.

Across the investigation, MD-4, MD-2 and MD-1 with respect to \%TDC, \%TDC.min, \%SumA:D and \%SumA:D.min were significantly higher as a percentage of MD data than any other metric analysed as part of the method. This suggests that these metrics may still be maintained to higher levels (21-48\%) when compared to the more explosive high- speed and sprinting activities (2-11\%) when reducing the TL across a typical competitive week. As cited previously, the requirement to continually perform high force eccentric actions such as changes in direction, accelerations and decelerations seems particularly damaging to the muscle (Raastad et al. 2010; Young et al. 2012; Silva et al. 2014). This study has revealed a higher SumA:D in MD-1 compared to MD-2 which, according to the literature in this area, increase the susceptibility of injury and may therefore be a negative aspect of the tapering strategy. This may be as a result of the related higher metabolic and explosive demands causing a higher injury risk (Opar et al. 2012). Accordingly, the present findings corroborate recent studies suggesting that match-tomatch variability of these two metrics was very high (coefficient of variation of $\sim 16-31 \%$ ), especially regarding the impact of team's possession, tactical demands, playing positions, period of the season (Gregson et al. 2010) and team's success might play on the physical output. It might be suggested that these metrics (HSR and SpD) are the most sensitive ones in relation to contextual factors, also in a training context.

Interestingly, when examining the session volume score in this study, apart from MD-3, every other TD revealed a higher relative \% intensity score versus \% volume score. This is an interesting issue raised based on the fact that across the 20week period assessed, the volume score outweighed the intensity score in line with the MD itself. The reason for this may be based on the fact that the greater total volume on this day (MD-3) plays a pivotal role in driving all the additional metrics to increased levels. It may also show that as the fatigue state of the player is increased based on the volume of the session, the subsequent intensity is reduced, again questioning the quality of the session based solely on intensity markers. Across the study, the fact that the relative intensity \% score across the week is higher on MD-4, MD-2, MD-1 may be as a result to the significantly lesser volume on these days in relation to MD.

\section{Conclusion}

This investigation proposed a contemporary and clear multimodal method to represent a tapering structure for both volume and intensity markers across an in-season microcycle amongst professional European soccer players. This study, which is the first of its kind, revealed significant differences between TLs (i.e., volume and intensity) across the microcycles assessed and as a result may be utilised as way of representing $\%$ daily variance and overloading in relation to MD values. Using this specific multi-modal approach may allow practitioners to combine key mechanical volume and intensity metrics assessed as part of their athlete or player monitoring strategies to vary the physical stressors depending upon the specific tapering or periodisation approach followed. Furthermore, the investigation also highlights a specific tapering strategy used in European professional soccer and highlights to practitioners a method of adding significant variance to $T L$ in relation to MD data. Based on the fact that there is limited amount of published literature in this area, coaches need to gain a better understanding of tapering strategies and 
furthermore understand the need to prepare players individually in line with the demand of match-play. Future research in this area should utilise this multi-modal mechanical monitoring method in attempt to highlight positional differences to further promote this method as a TL assessment strategy. In addition, future research could also report the findings across the microcycle in direct relation with the previous game data rather than maximum MD values. To conclude, this monitoring strategy brings together the key reported metrics from a mechanical perspective revealing a positive portrayal of a tapering strategy in order to identify differences between intensity and volume markers.

\section{Practical implications}

The present study demonstrates that the use and integration of a multimodal approach to monitoring TL in direct relationship with competitive soccer match-play at the elite level provides a better weekly review of both player intensity and volume markers. Despite the potential advantages of combining metrics to provide a simpler overview of the training response and stimulus provided, care should be considered based on the fact that further in-depth analysis may still be required in order to understand specific metric levels if an over- or under-load is reported within a tapering strategy. The practical implications may be further enhanced by understanding the day-to-day player variance, fitness and wellness state in accordance to the coaching demand corresponding to match-day activity. Continual TL monitoring across the pre- and in-season phases should be performed in order to prevent players from overreaching and overtraining. Coaches and physical conditioning staff may also further use this method in order to understand which important key metrics need to be stressed or developed to better prepare individual players for match demands.

\section{Disclosure statement}

No potential conflict of interest was reported by the authors.

\section{References}

Buchheit M. 2014. Monitoring training status with HR measures: do all roads lead to Rome? Front Physiol. 27:73.

Cohen J. 1988. Statistical power analysis for the behavioural sciences. 2nd ed. Hillsdale, NJ: Lawrence Erlbaum.

Dellal A, Chamari K, Wong DP, Ahmaidi S, Keller D, Barros R, Bisciotti GNCarling C. 2011. Comparison of physical and technical performance in european soccer match-play: fa premier league and la liga. European Journal Of Sport Science. 11:51-59.

Eirale C, Tol JL, Farooq A, Smiley F, Chalabi H. 2013. Low injury rate strongly correlates with team success in Qatari professional football. Br J Sports Med. 47:807-808.

Gabbett TJ. 2016. The training-injury prevention paradox: should athletes be training smarter and harder? Br J Sports Med. 50:273-280.

Gabbett TJ. 2016. The training-injury prevention paradox: should athletes be training smarter and harder?. Br J Sports med. 50:273-280.

Gaudino P, laia FM, Strudwick AJ, Hawkins RD, Alberti G, Atkinson G, Gregson W. 2015. Factors influencing perception of effort (session rating of perceived exertion) during elite soccer training. Int J Sports Physiol Perform. 10:860-864.

Gregson W, Drust B, Atkinson G, Salvo VD. 2010. Match-to-match variability of high-speed activities in premier league soccer. Int J Sport Med. 31:237-242.

Hill-Haas SV, Dawson B, Impellizzeri FM, Coutts AJ. 2011. Physiology of small-sided games training in football, a systematic review. Sports Med. 41:199-220.
Holm S. 1979. A simple sequentially rejective multiple test procedure. Scand J Stat. 6:65-70.

Impellizzeri FM, Rampinini E, Coutts AJ, Sassi A, Marcora SM. 2004. Use of RPE-based training load in soccer. Med Sci Sports Exerc. 36:1042-1047.

Issurin VB. 2010. New horizons for the methodology and physiology of training periodization. Sports Med. 40:189-206.

Jaspers A, Brink MS, Probst SGM, Frencken WGP, Helsen WF. 2017. Relationship between training load indicators and training outcomes in professional soccer. Sports Med. 47:533-544.

Jennings D, Cormack S, Coutts AJ, Boyd LAughey RJ. 2010. The validity and reliability of gps units for measuring distance in team sport specific running patterns. Int J Sports Phys And Performance. 5:328-341.

Kelly VG, Coutts AJ. 2007. Planning and monitoring training loads during the competition phase in team sports. Strength Cond J. 29:32-37.

Mallo J, Dellal A. 2013. Injury risk in professional football players with special reference to the playing position and training periodization. $J$ Inj Prev. Aug 20. 4:e8. doi:10.1136/injuryprev-2013-041092

Malone JJ, Di Michele R, Morgans R, Burgess D, Morton JP, Drust B. 2015. Seasonal training-load quantification in elite English premier league soccer players. Int J Sports Physiol Perform. 10:489-497.

Malone S, Owen A, Newton M, Mendes B, Collins KC, Gabbett TJ. 2016. The acute: chronic workload ratio in relation to injury risk in professional soccer. J Sci Med Sport. 20:561-565.

Opar MDA, Williams MD, Shield AJ. 2012. Hamstring strain injuries: factors that lead to injury and re-injury. Sports Med. 42:209-226.

Orchard JW. 2009. On the value of team medical staff: can the "moneyball" approach be applied to injuries in professional football? $\mathrm{Br} J$ Sports Med. 43:963-965.

Owen AL, Dunlop G, Rouissi M, Haddad M, Mendes B, Chamari K. 2016. Analysis of positional training loads (ratings of perceived exertion) during various-sided games in European professional soccer players. Int J Sports Sci Coaching. 11:1-8.

Owen AL, Forsyth JJ, Wong DP, Dellal A, Connelly S, Chamari K. 2015. Heart rate' based training intensity and its impact on injury incidence amongst elite level professional soccer players. J Strength Conditioning Res. 29:1705-1712.

Owen AL, Lagos-Penas C, Gómez MA, Mendes B, Dellal A. 2017. Analysis of a training mesocycle and positional quantification in elite European soccer players. Int J Sports Sci Coaching. 12:1-8.

Owen AL, Wong DP, Paul D, Dellal A. 2012. Effects of a periodized small-sided game training intervention on physical performance in elite professional soccer. J Strength Conditioning Res. 26:27482754.

Owen AL, Wong DP, Paul D, Dellal A. 2014. Physical and technical comparisons between various-sided games within professional soccer. Int J Sports Med. 35:286-292.

Raastad T, Owe SG, Paulsen G, Enns D, Overguard K, Crameri R, Kiil S, Belcastro A, Bergersen L, Hallen J. 2010. Changes in calpain activity, muscle structure, and function after eccentric exercise. J Med Sci Sports Exerc. 42:86-95.

Randers MB, Mujika I, Hewitt A, Santisteban J, Bischoff R, Solano R. 2010. Application of four different football match analysis systems: a comparative study. J Sport Sci. 28:171-182.

Scott BR, Lockie RG, Knight TJ, Clark AC, De Jonge J. 2013. A comparison of methods to quantify the in-season training load of professional soccer players. Int J Sports Physiol Perform. 8:195-202.

Silva JR, Rebelo A, Marques F. 2014. Biochemical impact of soccer: an analysis of hormonal, muscle damage, and redox markers during the season. Appl J Physiol Nutr Metabolism. 39:432-438.

van der Horst N, Smits DW, Petersen J, Goedhart EA, Backx FJ. 2015. The preventive effect of the Nordic hamstring exercise on hamstring injuries in amateur soccer players: study protocol for a randomised controlled trial. Am J Sports Med. 43:1316-1323.

Varley MC, Fairweather IH, Aughey RJ. 2012. Validity and reliability of GPS for measuring instantaneous velocity during acceleration, deceleration, and constant motion. J Sports Sci. 30:121-127.

Young WB, Hepner J, Robbins DW. 2012. Movement demands in Australian rules football as indicators of muscle damage. J Strength Conditioning Res. 26:492-496. 